\title{
Phytochemical Study and Protective effect of Diospyros lotus Against Carbon Tetrachloride-Induced Hepato and Nephro-Toxicity in Rats
}

\author{
Gehan Fawzy Abdel Raoof ${ }^{1, ~}$, Khaled Younes Mohamed ${ }^{2}$, Emam Waked $^{3}$, \\ Hesham Anwar Gomaa ${ }^{4,5}$ \\ ${ }^{1}$ Pharmacognosy Department, National Research Centre, Dokki, Giza, Egypt \\ ${ }^{2}$ Internal Medicine Department, Medical Division, National Research Centre, Giza, Egypt \\ ${ }^{3}$ Nephrology Department, Theodor Bilharz Research Institute, Cairo, Egypt \\ ${ }^{4}$ Biochemistry Department, Faculty of Pharmacy, Nahda University, Beni-Suef, Egypt \\ ${ }^{5}$ Pharmacology Department, College of Pharmacy, Jouf University, Sakakah, Saudi Arabia \\ Email address: \\ ahmedkhaled_1@hotmail.com (G. F. A. Raoof), gehankandeel9@yahoo.com (G. F. A. Raoof) \\ ${ }^{*}$ Corresponding author
}

\section{To cite this article:}

Gehan Fawzy Abdel Raoof, Khaled Younes Mohamed, Emam Waked, Hesham Anwar Gomaa. Phytochemical Study and Protective effect of Diospyros lotus Against Carbon Tetrachloride-Induced Hepato and Nephro-Toxicity in Rats. International Journal of Bioorganic Chemistry. Vol. 4, No. 1, 2019, pp. 19-23. doi: 10.11648/j.ijbc.20190401.14

Received: February 8, 2019; Accepted: March 8, 2019; Published: March 30, 2019

\begin{abstract}
The present work was carried out to studytheprotective effect of $70 \%$ methanolic extract of Diospyros lotus L. aerial parts against hepato and nephro-toxicity that was induced bycarbon tetrachloride. In addition, phytochemical screening, total phenolic, total flavonoid contents and proximate analysisof the aerial parts were determined. Methanol $(70 \%)$ extracts of the aerial parts of Diospyros lotus L. was prepared. Two main groups of rats were assigned which were normal and damaged liver groups that administrated CCl4 (carbon tetra chloride). Each group classified into 4 different groups normalcontrol: was received distilled water, positive control: was administered silymarin $(50 \mathrm{mg} / \mathrm{kg})$, and treated groups:were administered Diospyros lotus tested extract at two dose levels (150 and $300 \mathrm{mg} / \mathrm{kg}$ ) for 15 days. Serum alanine and aspartate aminotransferase activities were determined to evaluate hepatoprptective effect, while uric acid and creatinine levels were measured to study renal function protective effects. The results showed that the alterations induced by carbon tetrachloride were significantly restored by methanol extract of Diospyros lotus (150 and $300 \mathrm{mg} / \mathrm{kg})$ in dose dependant manner. Alkaloids, carbohydrates, tannins, flavonoids, saponins and unsaturated sterols and/or triterpenes were detected as the main active constituents of the methanol extract. It can be concluded that the $70 \%$ methanol extract of Diospyros lotus L. aerial parts has a significant protective effect against acute hepatotoxicity and nephro-toxicity induced by $\mathrm{CCl} 4$ in ratsso it can be used as a safe hepato-nephro protective drug.
\end{abstract}

Keywords: Carbon Tetrachloride, Diospyros Lotus, Hepatotoprotective, Nephro-Toxicity

\section{Introduction}

Liver is one of the most important organs in the human body which responsible forsecretion of bile and storage of vitamins, detoxification as well as fat, protein andcarbohydrate metabolism [1]. Hepatitis and Jaundice are two major hepatic disorders that considered the major worldwide health problems, which may lead to death [2]. Unfortunately, series side effects were induced by synthetic drugs that used in the treatment of liver diseases, so natural products can be used instead of synthetic drugs [3]. For decades, natural products are playing an important role in health care [4]. Drug induced liver toxicity is major health problem that challenges not only the pharmaceutical industry but also healthcare professionals [5]. The activity of hepatoprotective agents can be evaluated by the inhibition of free radical generation [6].

Genus Diospyros is widely distributed in tropical and 
subtropical area, all members of the genus are trees [7]. Diospyros species are known for their medicinal usesin folk medicine. All parts of these plants have been used for medicinal purposes e.g. the bark is bitter, febrifuge and astringent, the seeds are sedative, the fruits are astringent, cure biliousness and carminative andthe leaves are used for lumbago [8]. In Japan, Japanese persimmon D. kaki (Leaf extract)in combination with jasmine is used for making antitobacco smoking candies. The other research stated that triterpenoids that have been isolated from Diospyros species showed anti-inflammatory activity [9]. Diospyros lotus tree (family Ebenaceae) grows up to $9 \mathrm{~m}$ in height and around 6 $\mathrm{m}$ in width. In traditional medicine, $D$. lotus fruits was used as aa febrifuge, nutritive, laxative, sedative, astringent, antitussive, antitumor, antidiabetic and as antiseptic [10-12]. In addition, $D$. lotus fruits are used to treat hypertension, dry coughs and diarrhea [13]. Previous phytochemical studies of $D$. lotus revealed the presence of naphthoquinones, terpenes, non volatile acids andsome fatty acids [14-16].

To our knowledge, there is only one report dealing with theaerial parts of D. lotus which stated that the aerial parts of D. lotus showed antioxidant effect [17]. Hence the current study aims to investigate the chemical constituents of this part and evaluate itsprotective effect against carbon tetrachloride-induced hepato and nephro-toxicity in rats.

\section{Materials and Methods}

\subsection{Plant Material}

The aerial parts of Diospyros lotus L. were collected from the Agricultural Research Centre, Giza, Egypt in April 2016 during flowering and identified by Dr. Mohammed ElGebaly, Department of Botany, National Research Centre (NRC) and by Mrs. Tereez Labib Consultant of Plant Taxonomy at the Ministry of Agriculture and director of Orman botanical garden, Giza, Egypt. A voucher specimen No. 2457 is deposited in the herbarium of Agricultural Research Centre, Giza, Egypt.

\subsection{Preparation of the Plants Extracts}

Air-dried powder of Diospyros lotus L. aerial parts (1000 g) was extracted with methanol/distilled water $(70: 30, \mathrm{v} / \mathrm{v})$ several times at room temperature until exhaustion by maceration method. The extract was concentrated under reduced pressure to give $58 \mathrm{~g}$ of the crude extract.

\subsection{Phytochemical Screening}

Chemical tests were carried out on the methanolic extracts using standard procedure to identify the constituents as described by $[18,19]$.

\subsection{Total Phenolic Assay}

The total phenolic content (TP) was determined applying the Folin-Ciocalteu colorimetric method using gallic acid as a standard [20], and expressed as milligrams of gallic acid equivalents $(\mathrm{GAE}) / \mathrm{g}$ of the dry plant materials.

\subsection{Total Flavonoid Assay}

Total flavonoid content (TFC) was measured using an aluminum chloride colorimetric assay [21]. A calibration curve was established using quercetin as a standard. TFC was expressed as $\mathrm{mg}$ quercetin equivalent $(\mathrm{QE}) / \mathrm{g}$ of the dry plant materials.

\subsection{Proximate Analysis}

Percentages of moisture content, total ash, water soluble ash, acid-insoluble ash, and crude fiber values were assessed according to the official methods [22].

\subsection{Biological Evaluation}

\subsubsection{Animal}

Sprague Dawley rats of both sexes weighing 130-150 g were used throughout the experiments. Animals were housed under standard environmental conditions $\left(23 \pm 1^{\circ} \mathrm{C}, 55 \pm 5 \%\right.$ humidity, 12:12 hr light-dark cycle) and maintained with free access to water and a standard laboratory diet ad libitum. Animal care and the experimental protocols were approved by Institutional Animal Care and Use Committee and were in accordance with the guidelines of the International Association for the Study of Pain.

\subsubsection{Acute Toxicity Study}

The $\mathrm{LD}_{50}$ of methanol (70\%) extract of the aerial parts of Diospyros lotus was determined using rats. Male and female albino rats (10 rats in each group) were orally administered the tested extract at doses ranging from 1.0 to $5.0 \mathrm{~g} / \mathrm{kg}$. $\mathrm{LD}_{50}$ was calculated using Karber method [23]. Two dose levels of Diospyros lotus were chosen (150 and $300 \mathrm{mg} / \mathrm{kg}$ ) to determine the most effective dose at exerting physiological activity.

\subsubsection{Animal Grouping and Experimental Design}

Rats were assigned into two main groups: normal and damaged liver groups that administrated CCl4 (carbon tetra chloride). Each group classified into 4 different groups (6 rats in each): group 1: was control received distilled water, group 2 was administered silymarin $(50 \mathrm{mg} / \mathrm{kg})$, and groups $3 \& 4$ were administered Diospyros lotus tested extract at two dose levels (150 and $300 \mathrm{mg} / \mathrm{kg}$ ) for 15 days. The drug solutions or vehicle were administered orally by gastric intubation using syringe to assess the experiments. At the end of experimental period, rats were anaesthetized with ether according to the method described by Cocchetto and Bjornsson [24]. Blood samples were collected from orbital venous plexus in nonheparinized tubes, centrifuged at 3000 rpm for $15 \mathrm{~min}$, and blood sera were collected and stored at $20^{\circ} \mathrm{C}$ before they were analyzed.

\subsubsection{Biochemical Analysis}

Determination of serum alanine aminotransferase (ALT) activity Serum alanine aminotransferase (ALT) activity was assessed colorimetrically using a test reagent kit according to 
the method described by Reitman and Frankel [25]. Determination of serum aspartate aminotransferase (AST) activity Serum AST activity was assessed colorimetrically using a test reagent kit according to the method described by Reitman and Frankel [25]. Serum uric acid is the end product of purine metabolism, and is cleared through the kidney by glomerular filtration. Kit provides a convenient means for detecting uric acid in biological samples such as serum and urine. Pretreatment of samples are not required. Uric acid level can be measured using colorimetric method (at $570 \mathrm{~nm}$ ) according to the method of Barham and Trinder [26]. Creatinine is a breakdown product of creatine phosphate. Creatinine is produced and excreted at a constant rate, and blood creatinine is used to determine glomerular filtration rate. Creatinine is measured in biological fluids (serum and urine) according to the method of Bartles and Bohmer [27].

\subsubsection{Statistical Analysis}

Data were analyzed using one-way ANOVA. P-value $<0.05$ was considered statistically significant.

\section{Results and Discussion}

\subsection{Phytochemical Analysis}

Table 1 showed thatflavonoids, tannins, carbohydrates and/or glycosides as well as sterols and/or triterpenes were present in the aerial parts of Diospyros lotus L., while coumarins, saponinsand alkaloids and/or nitrogenous bases were absent.

Table 1. Results of phytochemical screening of the aerial parts of Diospyros lotus L.

\begin{tabular}{ll}
\hline Constituents & $\begin{array}{l}\text { The aerial parts of Diospyros } \\
\text { lotus } \boldsymbol{L} .\end{array}$ \\
\hline 1. Carbohydratesand/or Glycosides & $+\mathrm{ve}$ \\
2. Tannins & $++\mathrm{ve}$ \\
3. Alkaloids and/or nitrogenous bases & $-\mathrm{ve}$ \\
4. Flavonoids & $++\mathrm{ve}$ \\
5. Sterols and/or triterpenes & $+\mathrm{ve}$ \\
6. Saponins & $-\mathrm{ve}$ \\
7. Coumarins & $-\mathrm{ve}$ \\
\hline
\end{tabular}

+ ve:the presence of the constituents, - ve: the absence of the constituents, \pm ve: the presence of the constituents in minute amounts

\subsection{Total Phenolic and Flavonoids Contents}

The flavonoids play a vital role in protection of human from many diseases [28].

The result showed that total phenolic content of the aerial parts of Diospyros lotus L. was $20.5 \mathrm{mg}$ gallic acid equivalent / $\mathrm{g}$ of the dry plant materials, while the total flavonoid was $17.1 \mathrm{mg}$ quercetin equivalent (QE)/g of the dry plant materials.

\subsection{Proximate Analysis}

Table 2 showed the percentages of moisturecontent, crude fiber total ash, water soluble ash and acid-insoluble ash of the aerial parts of Diospyros lotus L.. From these results, it could be concluded that, these constants could be used as criteria for the purity of the in the aerial parts of Diospyros lotus L.

Table 2. Percentages of certain pharmacopoeial constants of the aerial parts of Diospyros lotus L.

\begin{tabular}{ll}
\hline Pharmacopoeial constants & The aerial parts of Diospyros lotus $\boldsymbol{L}$. \\
\hline \% Moisture & 7.23 \\
\% Crude fibre & 8.62 \\
\% Total Ash & 2.31 \\
\% Water-soluble ash & 1.14 \\
\% Acid-insoluble ash & 1.15 \\
\hline
\end{tabular}

\subsection{Acute Toxicity Study}

No symptoms of mortality or morbidity were reported by oral administration of $70 \%$ methanol extractDiospyros lotus $L$. aerial parts in doses up to $5 \mathrm{~g} / \mathrm{kg}$. This result stated that the tested plantis safe for use.

\subsection{Hepato-nephro Protective Effects}

Liver function was estimated by measuring the activity of ALT and AST. These enzymes are normally located in the cytosol of hepatocytes. The type and extent of hepatocellular damage can be detected when these enzymes are released in the plasma and increased their activity [1].

Liver enzymes significantly decreased in groups treated with $70 \%$ methanol extractofDiospyros lotus $L$. aerial parts (at both doses) comparing with control value and silymarin groups in dose dependant manner. As well as, ALT and AST significantly decreased in groups treated with silymarin (Table 3).

Creatinine serum concentration and uric acid level were decreased significantly in groups treated with the two doses of Diospyros lotus extract comparing with the control or silymaringroups.(Table 3).

Table 3. Effect of $70 \%$ methanol extract of Diospyros lotus L. aerial parts onkidney function and liver enzymes in serum of normal rats.

\begin{tabular}{lllll}
\hline Groups & AST & ALT & Uric acid & Creatinine \\
\hline Control & $44 \pm 1.13$ & $28.1 \pm 1.24$ & $1.30 \pm 0.06$ & $0.45 \pm 0.07$ \\
Silymarin 50 & $38 \pm 2.86^{*}$ & $23.2 \pm 1.77^{*}$ & $1.28 \pm 0.08$ & $0.40 \pm 0.03^{*}$ \\
D. lotus extract 150 & $39.9 \pm 1.21^{*}$ & $25.1 \pm 1.33^{*}$ & $1.23 \pm 0.09$ & $0.33 \pm 0.06^{*} \sharp$ \\
D. lotus extract 300 & $36.7 \pm 2.33^{*} \#$ & $22.8 \pm 1.24 * \#$ & $1.19 \pm 0.07 * \#$ & $0.36 \pm 0.09^{*} \#$ \\
\hline
\end{tabular}

One-way ANOVA, significant at P-value $\leq 0.05$; AST: aspartate aminotransferase, ALT: alanine aminotransferase.; \# Compared to silymarin treatment group; * Significantly different from control group 
which were detected by the marked increase in serum ALT and AST activities. So liver enzymes values significantly elevated in $\mathrm{CCL}_{4}$-toxicated rats than the other $\mathrm{CCL}_{4}$ toxicated treated groups. The result showed that the two dose levels of Diospyros lotus $L$. aerial parts extract resulted significant reduction in the elevated ALT and AST levels caused by $\mathrm{CCL}_{4}$ in dose dependant manner as compared to control and silymarin treated group (Table 4). CCL4 intoxication resulted in significant increasing inserum uric acid and creatinine levels. Treated groups with the two dose levels of Diospyros lotus extract significantly reduced creatinine value, but still lower than the reduction due to silymarin treatment (Table 4). The uric acid level was significantly elevated byCCL4treatment, however it was significantly decreased by pretreating with silymarin. The uric acid value wassignificantly reduced in groups treated withthe two dose levels of Diospyros lotus extract in a dose dependent manner compared with CCL4 or silymarin.

Table 4. Effect of 70\% methanol extract of Diospyros lotus L. aerial parts onkidney function and liver enzymes and in serum of hepatic damage rats.

\begin{tabular}{llll}
\hline Groups & AST & ALT & Uric acid \\
\hline CCL $_{4}$ & $90.4 \pm 2.2$ & $48.3 \pm 1.31$ & $2.62 \pm 0.03$ \\
Silymarin $50+\mathrm{CCL}_{4}$ & $69.3 \pm 1.78^{*}$ & $27.5 \pm 1.22^{*}$ & $1.94 \pm 0.06^{*}$ \\
D. lotus extract $150+\mathrm{CCL}_{4}$ & $67.3 \pm 0.55^{*}$ & $39.3 \pm 1.34 * \#$ & $1.85 \pm 0.06^{* \#}$ \\
D. lotus extract $300+\mathrm{CCL}_{4}$ & $63.8 \pm 0.35^{*} \#$ & $35.9 \pm 0.65^{* \#}$ & $1.79 \pm 0.07^{* \#}$ \\
\hline
\end{tabular}

One-way ANOVA test, significant at P-value $\leq 0.05: \mathrm{CCL}_{4}$ : carbon tetra chloride, AST: aspartate aminotransferase; ALT: alanine aminotransferase, ${ }^{*}$ compared to $\mathrm{CCL}_{4}$ - treatment group; \# compared to Silymarin treatment group.

So we conclude that all treatment groups had hepatoprotective andrenal function protective effects in both normal and hepatotoxic groups. This biological activityismay be due to its free radical scavenging effect as the plant is reported to have strong antioxidant activity (17). Moreover, preliminary phytochemical study revealed the presence of carbohydrates and/or glycosides, tannins, flavonoids, and unsaturated sterols and/or triterpenes as major active constituents. Furthermore, phenolicscontents of some medicinal plants play a vital role in liver homogenates [28]. Therefore the protective effect of plant extract against $\mathrm{CCl}_{4}$ hepatotoxicity may be attributed to the presence of these biologically active constituents, which also play an important role in its antioxidant activity.

\section{Conclusion}

This study aims to study theprotective effect of $70 \%$ methanolic extract of Diospyros lotus L. aerial partsagainst carbon tetrachloride-induced hepato and nephro-toxicity in rats. The results showed that the extract of Diospyros lotus $L$. aerial parts has a significant protective effect against acute hepato-toxicity and nephro-toxicity induced by $\mathrm{CCl}_{4}$ in rats, this effect may be due to its free radical scavenging effect. Therefore, this study aims to usethe methanolic extract of the aerial part of the plantas a safehepato-nephro protectivedrug

\section{Conflicts of Interest}

The authors declare that they have no competing interests.

\section{Acknowledgements}

We acknowledge to National Research Centre, Theodor Bilharz Research Institute, Nahda Universityand College of Pharmacy, Jouf University, Sakakah, Saudi Arabiafor using laboratory instruments in doing research.

\section{References}

[1] Ahsan, R., Monirul Islam, K. M., Musaddik, A., Hague, E., (2009). Hepatoprotective activity of methanol extract of some medicinal plants against carbon tetrachloride induced hepatotoxicity in albino rats. Glob J Pharmacol, 3(3): 116122.

[2] Nazeema, T. H., Brindha, V., (2009). Antihepatotoxic and antioxidant defense potential of Mimosa pudica. Int J Drug Discov, 1: 1-4.

[3] Manokaran, Jaswanth, A., Sengottuvelu, S., Nandhakumar, J., Duraisamy, R., Karthikeyan, D., et al. (2008). Hepatoprotective activity of Aervalanata Linn. againstparacetamol induced hepatotoxicity in rats. Res $\mathrm{J}$ Pharm Tech, 1(4): 398-400.

[4] Absar, A., Quershi, Prakash T et al. (2007). Hepatoprotective and Antioxidant activities of flowers of Calotropisprocera (Ait) r. Br. in $\mathrm{CCl} 4$ induced hepatic damage. Indian J Exp Biology, 45:304-310.

[5] Ajith, T. A., Janardhanan, K. K., (2002). Antioxidant and antihepatotoxicactivites of Phellinusrimosus (Berk) Pilat. J Ethanopharmacol, 81:387-391.

[6] Mohameed, S. T. S., Christina A. J. M., Chidambaranathan, N., (2008)Hepatoprotective activity of Annonasquamosa Linn. on experimental animal model. Int J App Res Nat Pro, 1(3):1-7.

[7] Uddin, G., Rehman, T. U., Arfan, M., Liaqat, W., Waliullah, et al. (2011) Antimicrobial, insecticidal and phytotoxic activities of Indigoferaheterantha roots. J Med Plants Res, 5: 58355839 .

[8] Pant, S., Samant, S. S., (2010). Ethanobotanical observation in the Momaula Reserve Forest of KoumounWest Himalaya, India. Ethnobotanical Leaflets 1493.

[9] Watt, J. M., Breyer-Brandwijk, M. G., (1932) The Medicinal and Poisonous Plants of South Africa. Postgrad Med J 8: 427.

[10] Simmons, A. E., (1972). Growing Unusual Fruit. David and Charles, NewYork, ISBN: 0-7153-5531-7. 
[11] Chopra, R. N., Nayar, S. L., Chopra, I. C., (1986). Glossary of Indian Medicinal Plants (Including the Supplement). I stEdn., Council of Scientific and Industrial Research, New Delhi.

[12] Ebrahimzadeh, M. A., Pourmorad, F., Bekhadnia, A. R., (2008). Iron chelating activity screening phenol and flavonoid content of some medicinal plants from Iran. African Journal of Biotechnology 7, 3188-3192.

[13] Bown, D., (1995). Encyclopaedia of Herbs and Their Uses. Dorling Kindersely, Ltd., London, ISBN: 07513-020-31. pp 342 .

[14] Ahmet, F. A., Kadioglu, A., (1998). Non volatile acid composition during fruits development of Diospyros lotus L. Turkish Journal of Botany 22, 69-72.

[15] Khasan, T., Matyukhina, L. G., Saltykova, I. A., (1976). Triterpenoids of Diospyros lotus. Chemistry of Natural compounds 11, 118-123.

[16] Yoshihira, K., Tezuka, M., Natori, S., (1971). Naphthoquinones derivatives from the Abenaceae. II. Isodiospyrin, bisisodiospyrin and mamegakinone from Diospyros lotus L and D. morrisianaHance. Chemical Pharmaceutical Bulletin 19, 2308-2313.

[17] Khaled, R., Maria, C. B. (2017). Biological Activities of Plants used in Egyptian Ethnopharmacology. Journal of Applied Pharmaceutical Science 7 (05): 046-050.

[18] Harbone, J. B., (1973). Phytochemical methods. London: Chapman and Hall, Ltd.; p 49.

[19] Sofowora, A., (1993) Medicinal plants and Traditional medicine in Africa., Ibadan, Nigeria: Spectrum Books Ltd, p 289.
[20] Siger A., Nogala-Kalucka M., Lampart-Szczapa E., (2008). The content and antioxidant activity of phenolics compounds in cold-pressed plant oils. J Food Lipids 15: 137-149.

[21] Zhishen, J., Mengcheng, T., Jianming, W., (1999). The determination of flavonoid contents in mulberry and their scavenging effects on superoxide radicals. Food Chem. 64: $555-559$.

[22] Egyptian Pharmacopoeia, (1984). General Organization for Governmental Printing Office, Ministry of Health, Cairo, Egypt, 31-33.

[23] Karber, (1931). Quantal Responses. Calculation of ED50. In: Turner RA. editor. Screening Methods in Pharmacology. New York and London: Acadmic Press; p. 63, 64.

[24] Cocchetto, D. M., Bjornsson, T. D., (1983). Methods for vascular access and collection of body fluids from the laboratory rat. J Pharm Sci, 72:465-492.

[25] Reitman, S., Frankel, S., (1957). Colorimetric method for aspartate and alanine transferases. Am J ClinPathol, 28:56-63.

[26] Barham, D., Trinder, P., (1972). An improved colour reagent for the determination of blood glucose by the oxidase system. Analyst, 97:142-145.

[27] Bartles, H., Bohmer, M., Heirli, C., (1972). Serum creatinine determination without protein precipitation. ClinChem Acta, 37:193-197.

[28] Hertog, M. L., Feskens, E. J., Hollman, P. H., Katan, M. B., Kromhout, D., (1993). Dietary antioxidants flavonoids and the risk of coronary heartdisease: the zutphen elderly study. Lancet, 342: 1007-1011. 